\title{
Süperior mezenterik arter sendromu: Olgu sunumu
}

\author{
The superior mesenteric artery syndrome: A case report
}

\author{
Ali SOLMAZ, Merve TOKOÇíN, Osman Bilgin GÜLÇİÇEK, Sinan ARICI, Aytaç BİRİCIK, Hakan YİĞİTBAŞ, Erkan YAVUZ, \\ Candaş ERÇETIN, Fatih ÇELEBİ
}

\section{ÖZET}

Süperior mezenterik arter (SMA) sendromu, diğer adıyla Wilkie sendromu, duodenum üçüncü kitanın süperior mezenterik arter proksimali ve aorta arasında sıkışmasına bağlı oluşan nadir bir mekanik intestinal obstrüksiyon sebebidir. İlk kez 1861 yılında Carl Freiherr von Rokitansky tarafından tanımlanmıştır. Bu sendrom, abdominal aorta ile SMA arasındaki açı $6^{\circ}-25^{\circ}$ (normal değer $38^{\circ}-56^{\circ}$ ) olduğunda görülür. Üst gastrointestinal sistem çalışmalarında yaklaşık \%0,3 oranında rastlanmaktadır. Klinik olarak belirgin semptomlara sebep olanlar1 \%0,01-0,08 civarındadır. Belirgin kilo kaybı ile birlikte bulantı, kusma, anoreksiya, epigastrik ağrı ve şişkinlik gibi semptomlara sebep olur. Tedavide konservatif ve cerrahi yöntemler kullanılır ve cerrahi yöntem olarak en sık duodenojejunostomi ameliyatı yapılır.

$\mathrm{Bu}$ yazıda, nadir görülen ve tanısı genellikle güç konan cerrahi tedavinin başarı ile uygulandığı SMAS'lu bir hastamızı sunacağız.

Anahtar Kelimeler: Süperior mezenterik arter sendromu, İntestinal obstrüksiyon, Duodenum

\begin{abstract}
The superior mesenteric artery (SMA) syndrome, Wilkie's syndrome, is produced by a mechanical obstruction of the duodenum when the third part of the duodenum is trapped between the aorta and the proximal part of SMA. It was first described by Carl Freiherr von Rokitansky in 1861. It is seen when the angle between the abdominal aorta and the SMA is $6^{\circ}-25^{\circ}$ (normal value: $38^{\circ}-56^{\circ}$ ). It is estimated to be seen in about $0.3 \%$ of upper gastrointestinal investigations, but only approximately 0.01-0.08\% are symptomatic. Symptoms are anorexia, bloating, nausea, vomiting, epigastric pain and weight
\end{abstract}

Ali Solmaz (凶), Merve Tokoçin, Osman Bilgin Gülçiçek, Sinan Arıcı, Aytaç Biricik, Hakan Yiğitbaş, Erkan Yavuz, Candaş Erçetin, Fatih Çelebi Genel Cerrahi Kliniği, Bağcllar Ĕgitim ve Araştırma Hastanesi,

Istanbul, Türkiye

e-mail:solmazali@hotmail.com

Gönderilme/Submitted: 12.04.2014 Kabul/Accepted: 13.07.2014 loss. Treatment is either conservative follow-up or surgery. Surgical treatment involves duodenojejunostomy.

In this article, we present a case of SMA syndrome treated by a surgical approach.

Keywords: Superior mesenteric artery syndrome, Intestinal obstruction, Duodenum

\section{Giriş}

Süperior mezenterik arter (SMA) sendromu, aorta ile süperior mezenterik arter (SMA) arasında akut açılanma oluşması sonucu, duodenumun bu iki arter arasında sıkışması nedeniyle oluşan nadir bir edinsel hastalıktır [1]. İlk kez 1861 yılında Carl Freiherr von Rokitansky tarafından tanımlanmıştır [2]. Abdominal aorta ile SMA arasında bulunan açının $6^{\circ}-25^{\circ}$ (normal değer:38 $38^{\circ}-56^{\circ}$ ) olduğu vakalarda görülür. Kilo kaybının farklı bir sonucu olan yağ dokusunun kaybı ve SMA'in akut açılanması etiyolojik faktör olarak kabul edilmektedir [3,4].

Klinik olarak çoğunlukla kusma, istahsızlık, erken doyma ve üst karın ağrısı ile karşımıza çıkar [5].

Tedavi olarak konservatif ya da cerrahi müdahale uygulanabilir. Konservatif tedavide hastanın beslenmesi, kilo alması ve böylece akut açılanmayı önleyecek şekilde yağ doku artışını sağlamak amaçlanır [5-7]. Cerrahi tedaviyi ise jejenuma pasaj geçişini sağlayacak by-pass ya da anastomoz teknikleri oluşturur $[4,5]$.

\section{Olgu Sunumu}

On sekiz yaşında erkek hasta acil servise bulantı, kusma ve epigastrik bölgede ağrı ile başvurdu. Başvuru öncesindeki hafta boyunca aralıklı olarak yaygın karın ağrısı, kusma ve iştahsızlık şikayetinin olduğu öğrenildi. Hasta mental 
retarde olup, ebeveyinleri tarafından uzun zamandır beslenme problemleri olduğu, son bir ayda yaklaşı $5 \mathrm{~kg}$ kilo kaybı olduğu belirtildi. Hastanın laboratuvar bulgularında özellik tespit edilmedi. Yapılan abdominal ultrasonografide mide ve duodenumun birinci ve ikinci kıtasında belirgin dilatasyon gözlendi. Kontrastlı batın bilgisayarlı tomografi (BT)'sinde, gastrik dilatasyon ve duodenum üçüncü kıtada darlık izlendi (Şekil 1). Çekilen kontrastlı üst batın magnetik rezonans görüntüleme (MRG)'sinde duodenum üçüncü kıtadaki bası bulgusu desteklendi (Şekil 2). Mide duodenum pasaj grafisinde de duodenumdan jejenuma geçişin ileri derece sinırlı olduğu gorüldü (Şekil 3). Yapılan üst gastrointestinal sistem endoskopisi normal olarak değerlendirildi.

Özgeçmişinde geçirilmiş batın ameliyatı öyküsü olmayan hasta mevcut bulgular eşliğinde primer üst gastrointestinal seviyede mekanik intestinal obstrüksiyona sebep olan SMAS ön tanısı ile operasyona alındı.

Göbek üstü orta hat insizyonu ile yapılan eksplorasyonda duodenum dördüncü kıtanın aorta ile SMA arasında sıkıştığı, bu bölgenin proksimalinde kalan mide ve duodenumun dilate olduğu gözlendi. Bu bulgularla SMA sendromu tanısı kesinleştirildi (Şekil 4). Batın içindeki diğer organlarda herhangi bir patolojiye rastlanmadı. Treitz bağı tespit edilip proksimal jejenumda gerginlik olmayacak şekilde darlı̆̆ın proksimal ve distali arasinda yan-yana duodenojejenostomi ameliyatı yapıldı. Enteral beslenmeyi tolere eden hasta postoperatif 4. gün taburcu edildi. Ameliyat sonrası 1. ay kontrolünde hastanın hiçbir şikayeti yoktu.

\section{Tartışma}

İlk olarak Rokitanski tarafından 1861 yılında tanımlanmış olan Wilkie sendromu olarak da bilinen SMA sendromu, aort ile SMA arasındaki yağ pediküllerinin kaybı ile iki arter arasındaki açının daralması sonucu $\left(6^{\circ}-25^{\circ}\right)$ duodenum üçüncü kıtanın sıkışmasıyla oluşan bir tablodur [1]. Normal olarak, SMA aortu ortalama 45 derecelik $\left(38^{\circ}-56^{\circ}\right)$ açı ile terk edip duodenum üçüncü kıtayı aortomesenterik vaskuler açı ile geçer. SMA etrafında bulunan yağ ve lenfatik doku normalde eksentrik doudenal sıkışmayı önleyen yeterli bir yastık görevi sağlar [1,2]. Kilo kaybı, yanık, anoreksiya nevroza, travma ve / veya uzamış yatak istirahati gibi nedenlerle bu yastıkçıkların kaybının SMA sendromu etyolojisinde yer aldığı düşünülmektedir [3].

Süperior mesenterik arter sendromu, tanısı zor olan sendromlardan biridir. Hastanın hikayesi ve muayenesinde patogonomik bulgular mevcut değildir. Hastamızda kliniğimize nonspesifik bulgular olan karın ağrısı, bulantı

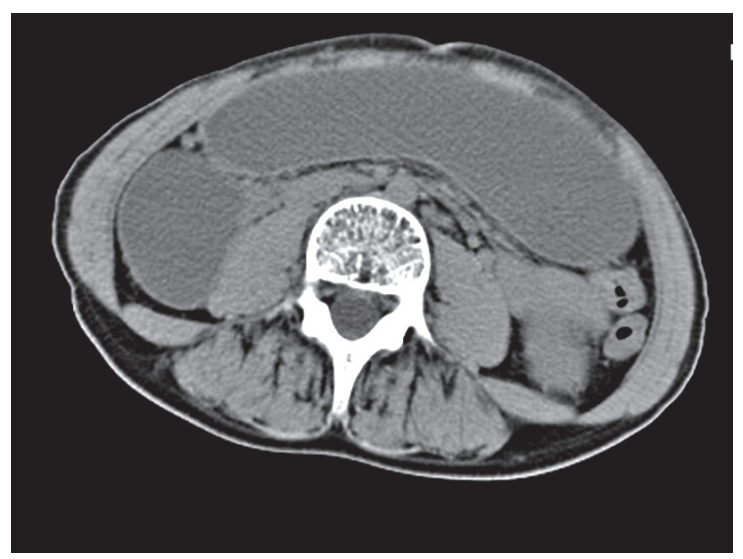

Şekil 1: Aksiyel kesitli batın tomografisinde obstrüksiyon proksimalindeki dilate duodenum segmentleri görülmektedir.

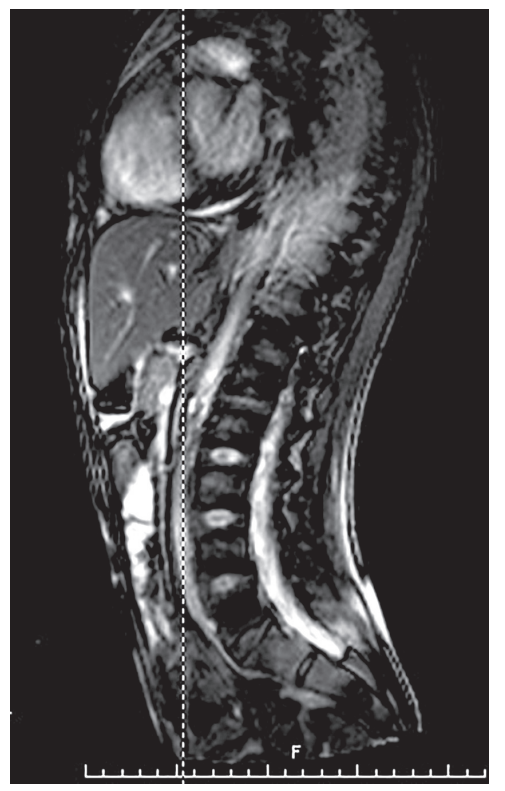

Şekil 2: Sagittal kesitte batın MRG'de SMA ile aort arasındaki açının daraldığ görülmektedir.

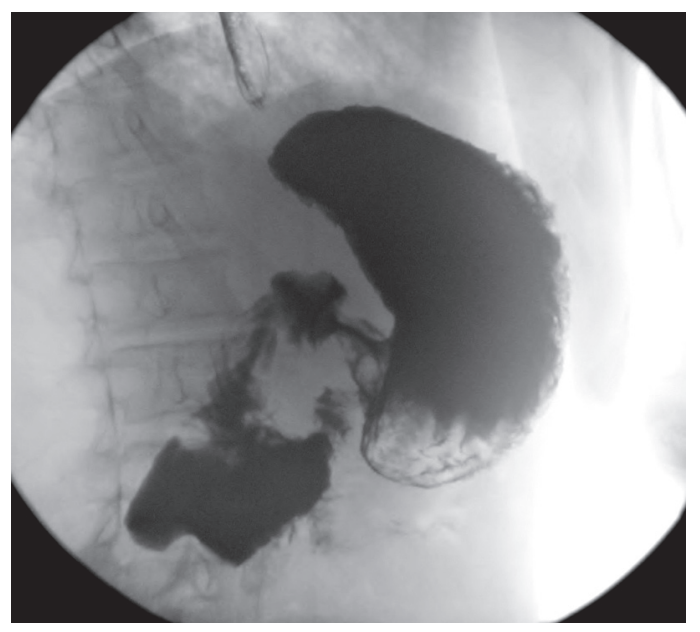

Şekil 3: Pasaj grafisinde duodenum üçüncü kıta düzeyi distaline kontrast geçişinin olmadığı görülmektedir. 


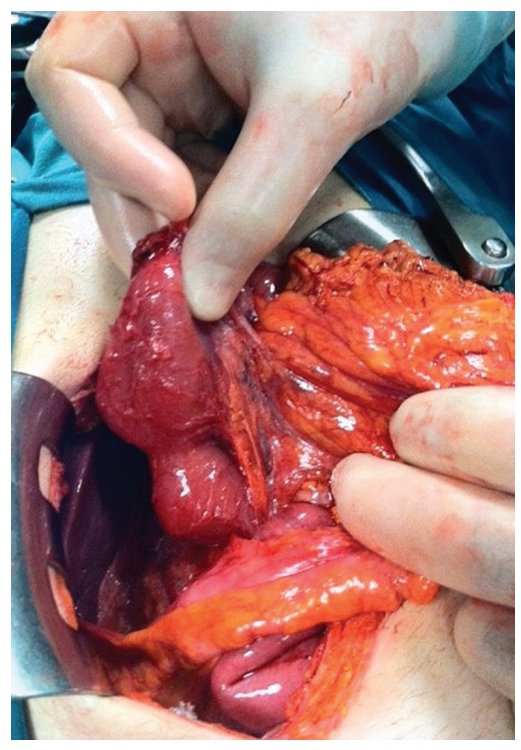

Şekil 4: SMA'nın sebep olduğu duodenal obstrüksiyona sekonder dilate olmuş duodenumun diğer segmentleri görülmektedir.

ve kusma gibi şikayetlerle başvurmuştur. Akut mekanik intestinal obstrüksiyon vakalarında; akut gastrik dilatasyon veya safralı kusma olması proksimal ince barsak tıkanıklığının bir bulgusu olarak karşımıza çıkabilir. Olguların çoğunda kusma, istahsızlık, erken doyma ve üst karın ağrısı gibi semptomlar mevcuttur [8]. Hastamızın özgeçmişinde de bu klinik bulguları saptanmıştır. Genellikle SMA ile aort arasındaki açıyı arttırmaya yönelik sol dekübit, diz-göğüs pozisyonu ya da yüzü koyun yatma gibi postural değişiklikler ile hastaların ağrısı hafifler [1]. Bizim hastamız da sol dekubit pozisyonda rahatlama göstermekteydi.

Yüksek şüphe varlığında erken tanı, masif gastrik dilatasyon, nekroz ve perforasyon gibi komplikasyonları önlemek için önemlidir. Direkt grafilerde dilate mide görülebilmekle birlikte spesifik değildir. Endoskopi, ancak obstruksiyonun intralüminal olduğu vakalarda tanıya yardımcıdır [9]. BT yardımlı duodenografi ve SMA arteriografi teknikleri günümüzde terk edilmiştir [5]. Dinamik BT, SMA ile aort arasında daralmış açıya bağlı duodenum sıkışmasını göstermede güvenli, hızlı, noninvaziv bir tanı aracıdır $[5,6,10]$. Bizim olgumuzda da kontrastlı üst batın BT'sinde, dilate mide ve duodenum üçüncü kıtada bası ile uyumlu bulgular izlendi. (Resim 1).

Tedavideki amaç, basının ortadan kaldırılması olup, konservatif yöntem olarak nazogastrik dekompresyon ve gastrointestinal hareketi arttırmaya yönelik ajanlar yer alır (7). Beslenme, sol lateral veya diz-göğüs pozisyonda veya nazojejunal veya total parenteral beslenme ile az, s1k ögünler şeklinde ve yüksek kalorili olmalıdır. Amaç mezenterik yağı arttırmak ve aortomesenterik açıyı genişletmektir. 6-8 haftalık tedavi neticesinde olumlu sonuç alınamazsa konservatif tedavinin başarısız olduğu düşünülerek cerrahi tedavi kararı verilir [5].

Literatürde değişik cerrahi teknikler tanımlanmıştır. Strong'un 1958 yılında tarif ettiği teknikte Treitz ligamanı disseke edilerek duodenum mobilize edilirdi [11]. Bu teknik anastomoz gerektirmemesine rağmen yüksek başarısızlık oranına sahip olduğu için günümüzde terk edilmiştir. Gastrojejenostomi yetersiz duodenum dekompresyonu ve ülser riskinin yüksek olması nedeniyle günümüzde uygulanmamaktadır. Duvie kalıcı tıkanıklığı aşmak için, duodenum üçüncü kıtanın superior mezenterik damarların anterioruna transpozisyonunu tanımlamıştır [12]. Her ne kadar kendisi tarafından ideal cerrahi yöntem olarak tarif edilse de günümüzde pek kullanılmamaktadır. İlk kez Staveley tarafindan 1910 yilında tanımlanan duodenojejunostomi tekniği günümüzde kabul gören bir yöntemdir [13]. Biz de hastamızda duodenojejunostomi tekniğini uyguladık.

Sonuç olarak, sebebi bilinmeyen bulantı, kusma ve kilo kaybı şikayetleri ile gelen ve üst gastrointestinal sistem düzeyinde tıkanıklık düşünülen hastalarda SMA sendromu ayırıcı tanıda dikkate alınmalıdır. Görüntüleme yöntemlerinden kontrastlı üst batın BT'sinde duodenumda dıştan bası şeklinde darlık ve pasaj grafisinde duodenum üçüncü kıta düzeyinde kısmi veya tam tıkanıklık tanı koydurucudur. Medikal tedavinin başarılı olmadığ 1 durumlarda duodenojejunostomi en yaygın kullanılan cerrahi yöntemdir.

Çıkar çatışması: Yazımızın tarafsızlığı ile ilgili bilinmesi gereken herhangi bir mali katkı veya diğer çıkar çatışma ihtimali (potansiyeli) yoktur.

\section{Kaynaklar}

1. Gniftiths GJ, Whitehouse GH, Wilkie DP. Chronic duodenal ileus. Br J Surg 1921;9:204.

2. Palanivelu C, Rangarajan M, Senthilkumar R, Parthasarathi R, Jani K. Laparoscopic duodenojejunostomy for superior mesenteric artery syndrome. JSLS 2006;10:531-4.

3. Laffont I, Bensmail D, Rech C, Prigent G, Loubert G, Dizien O. Late superior mesenteric artery syndrome in paraplegia: Case report and review. Spinal Cord 2002;40:88-91.

4. Kothari TH, Machnicki S, Kurtz L. Superior mesenteric artery syndrome. Can J Gastroenterol 2011;25:599-600.

5. Singaporewalla RM, Lomato D, Ki TK. Laparoscopic duodenojejunostomy for superior mesenteric artery syndrome. JSLS 2009;13: 450-4.

6. Wu MC, Wu IC, Wu JY, Wu DC, Wang WM. Superior mesenteric artery syndrome in a diabetic patient with acute weight loss. World J Gastroenterol 2009;15:6004-6.

7. Wilson-Storey D, MacKinlay GA. The superior mesenteric artery syndrome. J R Coll Surg Edinb 1986;31:175-8. 
8. Beltrán ODG, Martínez AV, Manrique MCP, Rodríguez JS, Febres EL, Peña SR. Superior mesenteric artery syndrome in a patient with Charcot Marie Tooth disease. World J Gastrointest Surg 2011; 3:197-200.

9. Bauer S, Karplus R, Belsky V, Amital H. Superior mesenteric artery syndrome: A forgotten entity. Isr Med Assoc J 2013;15:189-91.

10. Bermas H, Fenoglio ME. Laparoscopic management of superior mesenteric artery syndrome. JSLS 2003;7:151-3.
11. Strong EK. Mechanics of aortomesenteric duodenal obstruction and direct surgical attack upon etiology. Ann Surg 1958;148:725-30. doi: 10.1097/00000658-19581100000001.

12. Duvie SO. Anterior transposition of the third part of the duodenum in the management of chronic duodenal compression by the superior artery. Int Surg. $1988 ; 73: 140-3$.

13. Jones PA, Wastell C. Superior mesenteric artery syndrome. Postgrad Medical J 1983;59:376-9. 